\title{
Qualitative Profile of Volatile Compounds by SPME in Dendrocalamus latiflorus, Phyllostachys pubescens, and Phyllostachys makinoi Culms Used as Eating Utensils
}

\author{
Minjay Chung, ${ }^{a}$ Sensung Cheng, ${ }^{a}$ Chunya Lin, ${ }^{\mathrm{b}, \mathrm{c}}$ and Shangtzen Chang ${ }^{\mathrm{b}, *}$ \\ Volatile compounds are released when bamboo culms are used as \\ eating utensils. Volatile compounds of Dendrocalamus latiflorus, \\ Phyllostachys pubescens, and $P$. makinoi culms were extracted using \\ solid-phase microextraction (SPME). The bamboo culms were steamed \\ or baked at different temperatures $\left(100^{\circ} \mathrm{C}\right.$ and $\left.230^{\circ} \mathrm{C}\right)$ and durations $(5$ \\ $\mathrm{min}, 30 \mathrm{~min}$, and $60 \mathrm{~min}$ ). Gas chromatography-mass spectrometry (GC- \\ MS) analyses showed that, regardless of heating method and duration, \\ $P$. makinoi culms comprised the most species of volatile compounds, \\ with sesquiterpenes being the major compounds. Steaming and baking \\ $D$. latiflorus culms at $100^{\circ} \mathrm{C}$ for 30 min yielded more volatile compounds \\ than baking at $230{ }^{\circ} \mathrm{C}$. Benzenoids were the chief compounds in heated \\ $D$. latiflorus and $P$. pubescens culms, with phenylacetaldehyde being the \\ dominant constituent. Phenylacetaldehyde has fragrances of herb, \\ flower, and oil. Moreover, the major volatile compound cyclosativene, \\ which gives a terpene-like aroma, was obtained when $P$. makinoi culms \\ were heated for different durations. After baking at $230^{\circ} \mathrm{C}$ for $30 \mathrm{~min}$, the \\ major volatile compound released from $P$. makinoi culm was $\alpha$ - \\ muurolene $(41.19 \%)$, which produces a woody aroma. After continuous \\ baking for $60 \mathrm{~min}$, DT 1, a kind of diterpene compound, increased \\ remarkably in relative content, while the content of a-muurolene \\ decreased notably.
}

Keywords: Dendrocalamus latiflorus; Phyllostachys pubescens; Phyllostachys makinoi; GC-MS; Solidphase microextraction; Volatile compounds

Contact information: a: Experimental Forest, National Taiwan University, No. 12, Section 1, Chien-Shan Road, Chu-Shan, Nantou Hsien, 55750, Taiwan; b: School of Forestry and Resource Conservation, National Taiwan University, Taipei 10617, Taiwan; c: Department of Wood Based Materials and Design, National Chiayi University, Chiayi City 60004, Taiwan; *Corresponding author: peter@ntu.edu.tw

\section{INTRODUCTION}

Widely distributed around the world, bamboo, with its advantages of rapid and abundant growth, is an important forest resource. Being the main product of bamboo cultivation, bamboo culms have been extensively used as fiber and construction materials, or further processed into laminated/composite bamboo plates, bamboo charcoal, musical instruments, household utensils, bamboo veneer, and panels, agricultural tools or woven products (Huang et al. 2016). As seen in the broad range of utilization, bamboo cultivation and processing have realized the ideal of "green manufacturing" with full exploitation of useful resources and waste materials recycled. In Taiwan, there are many species of bamboos, which are widely distributed from the coastlines to the mountains. Among them, 
ma bamboo (Dendrocalamus latiflorus Munro), moso bamboo (Phyllostachys pubescens Mazel), and makino bamboo (P. makinoi Hayata) are the three most dominant and valuable bamboo species. These bamboo culms also have long been used as eating utensils. Apart from their being plentiful and readily available for utilization, bamboo culms when heated release distinctive aroma, adding fragrance to the food contained or cooked in them. A well-known dish is rice stuffed in bamboo culms, which can be cooked by steaming, baking, or grilling.

Among the various approaches for extracting volatile organic compounds such as phytoncides and essential oils, solid-phase microextraction (SPME) is the most widely employed (Yang and Peppard 1994; Hsu et al. 2006; Chung et al. 2008). SPME involves the use of a fiber coating, which extracts different kinds of components (both volatile and non-volatile) from different kinds of media that can be in liquid or gas phase. It is a simple and inexpensive technique with no need of solvents (Steffen and Pawliszyn 1996; Chen et al. 2010; Chung et al. 2012). In view of its convenience in implementation and wide application in many areas, this study used SPME to extract volatile components of $D$. latiflorus, $P$. pubescens, and $P$. makinoi culms. The volatile compounds at ambient temperature were determined using gas chromatography-mass spectrometry (GC-MS).

In addition, the effects of different heating methods, i.e., steaming and baking, on volatile compounds and characteristic fragrances released from bamboo culms were investigated. Steaming and baking are the two most common methods for cooking bamboo in Taiwan. As mentioned above, bamboo culms stuffed with rice and then steamed or baked/grilled at temperatures greater than $200{ }^{\circ} \mathrm{C}$ give off an attractive fragrance that makes the rice more "appetizing." Hakkou et al. (2005) investigated chemical modifications and molecular organization of wood biopolymers and reported that generation of extractives by heat treatment begins at $160{ }^{\circ} \mathrm{C}$ and becomes important at temperatures greater than $200{ }^{\circ} \mathrm{C}$. In addition to investigating the effects of different heating temperatures, the three bamboo culms were also steamed and baked for different durations to examine the variations in volatile compounds. The results thus obtained can shed light on distinctive aromas released by D. latiflorus, $P$. pubescens, and $P$. makinoi culms when heated and provide useful references for promoting their use in cuisine preparation.

\section{EXPERIMENTAL}

\section{Materials}

Three-year-old culms of Dendrocalamus latiflorus Munro (ma bamboo), Phyllostachys pubescens Mazel (moso bamboo), and P. makinoi Hayata (makino bamboo) were obtained in September 2014 from the Xitou tract of the Experimental Forest of National Taiwan University. When harvested, the fresh bamboo culms were washed and then stored in a sealed bag at $-80{ }^{\circ} \mathrm{C}$ without exposure to light prior to analysis.

\section{Methods}

Treatment conditions

To examine the changes in composition and relative contents of volatile constituents under ambient temperature $\left(25^{\circ} \mathrm{C}\right)$, different heating methods and durations, volatile compounds present in D. latiflorus, P. pubescens, and P. makinoi culms were 
extracted using SPME after steaming and baking at different temperatures $\left(100{ }^{\circ} \mathrm{C}\right.$ and 230 ${ }^{\circ} \mathrm{C}$ ) and for different durations (5 min, $30 \mathrm{~min}$, and $60 \mathrm{~min}$ ).

\section{Extraction of volatile compounds}

The manual SPME device and $65 \mu \mathrm{m}$ polydimethylsiloxane-divinylbenzene (PDMS/DVB) fiber with length in $1.0 \mathrm{~cm}$ used in this study were purchased from Supelco Co. (Bellefonte, PA, USA). The PDMS/DVB fiber was conditioned as recommended by the manufacturer prior to the extraction. Fresh D. latiflorus, $P$. pubescens, and $P$. makinoi culms weighing $30 \mathrm{~g}$ were placed a $500-\mathrm{mL}$ flask closed by an aluminum foil, and then heated by steaming or baking. It took place by placing the PDMS/DVB fiber in the space between the vegetal material and the aluminum foil. The adsorption time of each extraction was held for $30 \mathrm{~min}$ at different temperatures, and desorption at the gas chromatography (GC) inlet was for $5 \mathrm{~min}$ at $250{ }^{\circ} \mathrm{C}$.

\section{GC-MS analyses}

Volatile compounds present in bamboo culms were analyzed by a Trace GC PoLaris Q mass instrument (ion source temperature $230{ }^{\circ} \mathrm{C}, 70 \mathrm{eV}$ ) (Thermo Fisher Scientific, Waltham, MA, USA) equipped with a DB-5ms capillary column (Crossbond 5 $\%$ phenyl methylpolysiloxane) with a length of $30 \mathrm{~m}$, diameter of $0.25 \mathrm{~mm}$, and film thickness of $0.25 \mu \mathrm{m}$. The oven temperature was held at $40{ }^{\circ} \mathrm{C}$ for $4 \mathrm{~min}$, then programmed to increase from $40{ }^{\circ} \mathrm{C}$ to $250{ }^{\circ} \mathrm{C}$ at a rate of $4{ }^{\circ} \mathrm{C} / \mathrm{min}$, and then held for $5 \mathrm{~min}$. Other parameters included injector temperature, $250{ }^{\circ} \mathrm{C}$; carrier gas, helium at a flow rate of 1 $\mathrm{mL} / \mathrm{min}$; split ratio, 1:30; and scan range, 50 to $400 \mathrm{amu}$. Each analysis takes about 46.67 min. Identification of the major components of D. latiflorus, P. pubescens, and P. makinoi culms was confirmed by comparison against standards, by spiking, and on the basis of their mass spectral fragmentation using the Wiley 7.0 and National Institute of Standards and Technology (NIST) V2.0 (Adams 2007) databases. The information of the standard compounds used for ingredient identification are as follows: $\alpha$-pinene (purity 97\%), $p$ cymene (99\%), limonene (92\%), indole (99\%), E-nerolidol (96\%), and benzaldehyde (98\%) were purchased from Acros Organics (Belgium); n-nonanol (98\%), n-nonanal (95\%), and trans-2-nonenal (97\%) were purchased from Aldrich (U.S.A); 2-pentyl furan (98\%), phenylacetaldehyde (95\%), and $n$-decanal $(96 \%)$ were purchased from Alfa Aesar (U.S.A); cis-2-hexen-1-ol (90\%), acetophenone (95\%), and $\alpha$-copaene (90\%) were purchased from Fluka (U.S.A); trans- $\beta$-caryophyllene and methyl salicylate were purchased from TCI (Japan); vanillin and trans- $\beta$-ocimene were purchased from Merck (Germany) and SAFC (U.S.A), respectively. Quantification was performed by percentage peak area calculations using the GC-FID. In addition, the Kovats index (KI) was also calculated (Eq. 1),

$$
K I=100 N+100 \frac{\log t_{\mathrm{R}(\mathrm{X})}-\log \mathrm{t}_{\mathrm{R}(N)}}{\log t_{\mathrm{R}(N+1)}-\log t_{\mathrm{R}(N)}^{\prime}}
$$

where $t^{\prime}{ }_{\mathrm{R}(N)}$ and $t_{\mathrm{R}(N+1)}$ are the adjusted retention time for $N$ and $N+1$ carbon atoms, respectively in $n$-alkanes; and $t^{\prime}{ }_{\mathrm{R}(\mathrm{X})}$ is the adjusted retention time for an unknown compound $\mathrm{X}$. $t^{\prime}{ }_{\mathrm{R}(\mathrm{X})}$ should fall between $t^{\prime}{ }_{\mathrm{R}(N)}$ and $t_{\mathrm{R}(N+1)}$. 


\section{RESULTS AND DISCUSSION}

\section{Volatile Aromatic Compounds of Three Bamboo Culms}

Table 1 lists the volatile components extracted by SPME at $25{ }^{\circ} \mathrm{C}$ from the culms of the three bamboo species. The bamboo culms of the three species studied had large variations in both the number and relative contents of compounds present. Results revealed that 6, 5 and 6 main volatiles were identified in the D. latiflorus, $P$. pubescens, and $P$. makinoi, respectively. Their major compounds and relative contents were limonene $(30.03 \%)$, indole $(60.48 \%)$, and cyclosativene $(28.60 \%)$, respectively.

Table 1. Volatile Compounds Obtained from Bamboo Culms of $D$. latiflorus, $P$. pubescens, and $P$. makinoi by SPME at $25^{\circ} \mathrm{C}$

\begin{tabular}{|c|c|c|c|c|c|c|}
\hline \multirow{2}{*}{$\begin{array}{l}\text { R.t. } \\
\text { (min) }\end{array}$} & \multirow{2}{*}{$\mathrm{KI}^{\mathrm{a}}$} & \multirow{2}{*}{$\mathrm{rKI}{ }^{\mathrm{b}}$} & \multirow{2}{*}{ Compounds } & \multicolumn{3}{|c|}{ Relative content (\%) } \\
\hline & & & & D. latiflorus & P. pubescens & P. makinoi \\
\hline 9.87 & 861 & 859 & cis-2-Hexen-1-ol & $21.92 \pm 1.91$ & & \\
\hline 11.00 & 934 & 939 & $\alpha$-Pinene & & & $8.14 \pm 0.61$ \\
\hline 14.77 & 1024 & 1025 & p-Cymene & $10.51 \pm 1.24$ & & $7.59 \pm 0.98$ \\
\hline 14.95 & 1029 & 1029 & Limonene & $30.03 \pm 2.92$ & & $16.40 \pm 0.98$ \\
\hline 16.26 & 1060 & 1057 & $\begin{array}{c}\alpha \text {-Methyl benzene } \\
\text { Methanol }\end{array}$ & $23.48 \pm 1.02$ & & \\
\hline 15.23 & 1063 & 1059 & Acetophenone & $10.57 \pm 1.73$ & & \\
\hline 18.08 & 1171 & 1165 & n-Nonanol & $3.51 \pm 1.74$ & & \\
\hline 24.81 & 1289 & 1290 & Indole & & $60.48 \pm 5.12$ & \\
\hline 27.42 & 1366 & 1371 & Cyclosativene & & & $28.60 \pm 3.49$ \\
\hline 29.16 & 1417 & 1419 & $\begin{array}{c}\text { trans- } \beta- \\
\text { Caryophyllene }\end{array}$ & & $2.19 \pm 1.16$ & \\
\hline 29.68 & 1434 & 1439 & $\alpha$-Guaiene & & $12.47 \pm 7.52$ & \\
\hline 31.66 & 1496 & 1500 & $\alpha$-Muurolene & & & $23.16 \pm 0.65$ \\
\hline 32.13 & 1511 & 1513 & $y$-Cadinene & & $1.04 \pm 0.51$ & \\
\hline 33.60 & 1560 & 1563 & E-Nerolidol & & $19.35 \pm 6.64$ & \\
\hline 36.80 & 1671 & 1676 & Cadalene & & & $9.35 \pm 2.32$ \\
\hline \multicolumn{4}{|c|}{ Identified components (\%) } & 100 & 95.53 & 93.24 \\
\hline
\end{tabular}

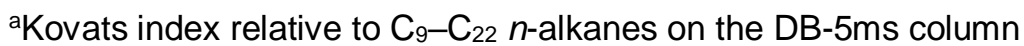

bIdentification according to comparison of the mass spectrum, Kovats index on a DB-5ms column in Adams (2007), and co-injection with authentic compounds

R.t.: Retention time (min)

Limonene (30.03\%) is the major volatile compound of $D$. latiflorus. It is known as a kind of cyclic terpene, thus giving $D$. latiflorus a characteristic odor of pungent green and fresh citrus-like (Tu et al. 2002; Choi 2006; Costa et al. 2008; Maraval et al. 2008). Ibrahim et al. (2001) indicated that bioactive limonene, in addition to its use as an insecticide to control ectoparasites of pet animals, also has activity against many insects, mites, and microorganisms. Possible attractive effects of limonene to natural enemies of pests offer novel applications to use natural compounds for manipulation of beneficial animals in organic agriculture (Ibrahim et al. 2001). The culm of D. latiflorus stores abundant nutrients and sugar for its growth; hence, the limonene in it may release odor for driving insects away. Besides, prior studies also reported limonene-containing essential oils exhibiting cancer chemopreventive activity (Elson et al. 1988; Crowell 1999) as well as sedative and motor relaxant effects (do Vale et al. 2002; Setzer et al. 2006). 
Indole, the main compound in P. pubescens, has a characteristic odor for similar self-defense function. Wang et al. (2008) identified in oolong tea this aroma-active compound that gives a nutty floral odor. Yang et al. (2008) examined the odor-active compounds in cooked black rice and reported indole as one of the nitrogen-containing compounds conferring a mothball odor. In the study of Takahashi et al. (2010) not only abundant indole was found in bamboo stems, its mothball-like odor was also the most intense among 18 aroma compounds detected in bamboo culms oil. Being an alkaloid commonly found in terrestrial and marine plants, indole displays cytotoxic properties as a protection against biological hazards.

Among the six volatile compounds in $P$. makinoi, the three main ones are cyclosativene (28.60\%), $\alpha$-muurolene (23.16\%), and limonene (16.40\%). In Helichrysum arenarium oil, which contains cyclosativene, Rančić et al. (2005) observed antimicrobial activity against bacterial and yeast species. $\alpha$-Muurolene was found in essential oils of propolis collected from five different locations in Greece (Maraval et al. 2008; Manzo et al. 2014). These oils also had antimicrobial properties with strong fungicidal activity. In summary, D. latiflorus, $P$. pubescens, and $P$. makinoi all exhibit different aroma at ambient temperature depending on their respective dominant constituents. These volatile compounds endow the bamboo with insect-repelling and anti-microbial properties, which offer good protection and defense against hazards, thus ensuring better survival and healthy growth.

\section{Effects of Heating Temperature on Volatile Compounds of Three Bamboo Culms}

Figure 1 compares the volatile compounds obtained by SPME from three bamboo culms steamed or baked at different temperatures for $30 \mathrm{~min}$. As can be seen, baking treatment at $100{ }^{\circ} \mathrm{C}$ yielded the highest numbers of volatile compounds, 17 in D. latiflorus, 15 in $P$. pubescens, and 24 in $P$. makinoi culms, with the major constituent being benzenoids, $\mathrm{N}$ compounds, and sesquiterpenes, respectively.

\section{Component content (\%)}

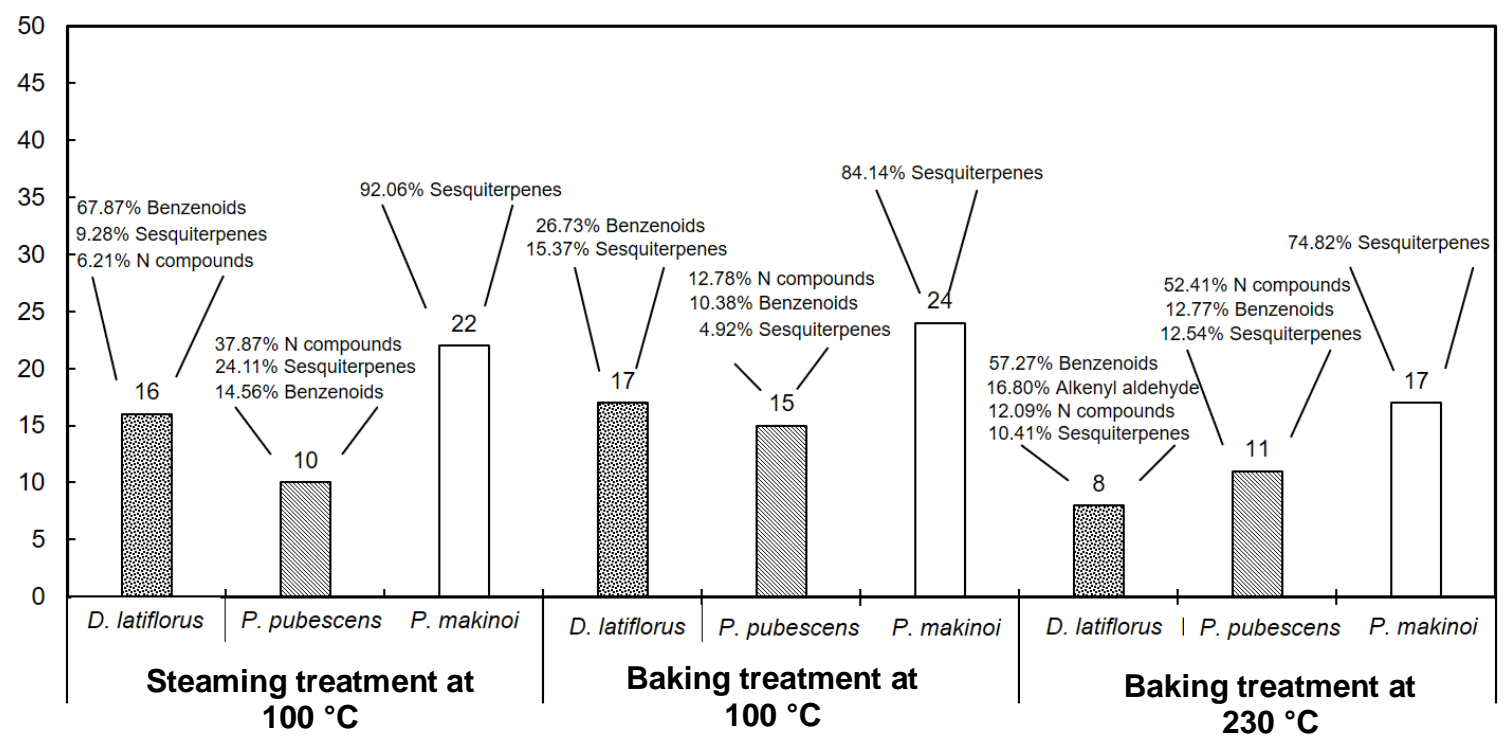

Fig. 1. Major volatile compounds and their relative contents (\%) of $D$. latiflorus, P. pubescens, and P. makinoi culms after steaming and baking for $30 \mathrm{~min}$ 
Table 2. Major Constituents and Their Relative Contents (\%) of D. latiflorus, P. pubescens, and P. makinoi Culms after Steaming and Baking for 30 min

\begin{tabular}{|c|c|c|c|c|c|c|c|c|c|}
\hline \multirow{2}{*}{ Compounds } & \multicolumn{3}{|c|}{ Steaming at $100^{\circ} \mathrm{C}$} & \multicolumn{3}{|c|}{ Baking at $100^{\circ} \mathrm{C}$} & \multicolumn{3}{|c|}{ Baking at $230{ }^{\circ} \mathrm{C}$} \\
\hline & D. latiflorus & P. pubescens & P. makinoi & D. latiflorus & P. pubescens & P. makinoi & D. latiflorus & P. pubescens & P. makinoi \\
\hline trans-2-Hexen-1-al & & & & $15.30 \pm 8.29$ & & & & & \\
\hline 2-Pentyl furan & & & & $17.35 \pm 1.98$ & $1.22 \pm 0.37$ & & & & \\
\hline Phenylacetaldehyde & $52.04 \pm 2.68$ & $12.77 \pm 2.71$ & & $21.22 \pm 5.87$ & $8.04 \pm 0.31$ & & $48.42 \pm 2.45$ & $10.74 \pm 0.32$ & $2.27 \pm 0.83$ \\
\hline trans- $\beta$-Ocimene & & & & $5.33 \pm 1.16$ & & & & & \\
\hline$\alpha$-Methyl benzene methanol & $4.06 \pm 1.29$ & & & & & & & & \\
\hline$n$-Nonanal & & $2.54 \pm 1.57$ & & & & & $10.70 \pm 3.65$ & $0.82 \pm 0.14$ & \\
\hline 2-Methoxy-p-cresol & $2.22 \pm 0.44$ & & & & & & $2.64 \pm 0.51$ & & \\
\hline Methyl salicylate & $3.98 \pm 1.28$ & $1.80 \pm 0.64$ & & $5.51 \pm 3.02$ & $0.92 \pm 0.51$ & & $6.25 \pm 2.51$ & $1.79 \pm 0.34$ & \\
\hline$n$-Decanal & $2.39 \pm 0.68$ & & & & $1.28 \pm 0.41$ & & $6.10 \pm 1.59$ & & \\
\hline Indole & $6.21 \pm 1.81$ & $37.87 \pm 2.93$ & & $4.30 \pm 2.43$ & $12.78 \pm 4.27$ & & $12.09 \pm 2.75$ & $52.41 \pm 2.02$ & $5.24 \pm 2.76$ \\
\hline Cyclosativene & & & $\begin{array}{c}48.21 \pm \\
2.86\end{array}$ & $6.80 \pm 2.52$ & & $30.85 \pm 3.02$ & & & $20.24 \pm 1.12$ \\
\hline$\alpha$-Copaene & & & $6.16 \pm 1.38$ & & & $2.43 \pm 0.09$ & & & \\
\hline Vanillin & $3.18 \pm 0.63$ & & & & & & & & \\
\hline$\alpha$-Guaiene & & $19.69 \pm 2.01$ & & & $10.16 \pm 1.74$ & & & $11.17 \pm 2.87$ & \\
\hline Valencene & $2.58 \pm 2.25$ & & & & & & & & \\
\hline$\beta$-Selinene & & & & & & $15.44 \pm 1.77$ & & & \\
\hline$\alpha$-Selinene & & & & & & $9.72 \pm 0.13$ & & & \\
\hline$\alpha$-Muurolene & $2.71 \pm 2.45$ & & $\begin{array}{c}27.49 \pm \\
2.44 \\
\end{array}$ & $2.88 \pm 1.53$ & & $13.49 \pm 2.15$ & & & $41.19 \pm 2.02$ \\
\hline Cedrol & $3.99 \pm 0.86$ & & & $3.74 \pm 1.24$ & & & $10.41 \pm 2.42$ & & \\
\hline
\end{tabular}


Benzenoids are aromatic compounds, thus accounting for the fragrance of $D$. latiflorus when heated. In addition to considering the number of volatile components measured, in practice, steamed or baked D. latiflorus is indeed more aromatic than heated $P$. pubescens and $P$. makinoi. Such difference can be attributed to the greater relative content of benzenoids in $D$. latiflorus compared with the other two species of bamboo.

Table 2 lists the volatile aromatic compounds released from the bamboo culms after the 30-min heat treatment. Regardless of the heating method or temperature used, phenylacetaldehyde was the major aromatic compound in D. latiflorus after being heated. Abel et al. (2009) reported phenylacetaldehyde as the predominant volatile constituent of Arabidopsis lyrata ssp. petraea collected in Germany and the major floral volatile constituent in the North American subspecies A. lyrata ssp. lyrata. Commonly found in many plants, phenylpropanoids give a floral scent that attracts pollinating insects and bees (Abel et al. 2009). In addition to plants, boiled beef has also been found to contain phenylacetaldehyde that gives an herby odor (Moon et al. 2006).

In $P$. pubescens, whether steamed or baked, indole ranked highest in relative content, followed by $\alpha$-guaiene and phenylacetaldehyde. These results echoed those in the study of Takahashi et al. (2010). They found that the volatile compounds of moso bamboo stem oil were mainly fatty acid (29.3\%), followed by alcohols $(20.9 \%)$, aldehydes $(11.5 \%)$, and hydrocarbons $(10.8 \%)$. The chemical constituent $\alpha$-guaiene was identified, and aromaactive compounds, including indole with a mothball-like odor and phenylacetaldehyde with a floral scent, were also detected. Wang et al. (2008) identified both indole with a nutty aroma and phenylacetaldehyde with a lilac fragrance in oolong tea. Moreover, they reported increased indole concentration with fermentation and used it as one of the indices for distinguishing unfermented and fermented teas.

Variations in dominant volatile compounds were observed in P. makinoi heated using different methods and temperatures. As shown in Table 2, P. makinoi steamed at 100 ${ }^{\circ} \mathrm{C}$ for $30 \mathrm{~min}$ comprised mainly cyclosativene $(48.21 \%)$, followed by $\alpha$-muurolene $(27.49 \%)$ and $\alpha$-copaene $(6.16 \%)$. In contrast, $\alpha$-muurolene $(41.19 \%)$ was the major constituent, followed by cyclosativene $\left(20.24 \%\right.$ ), in $P$. makinoi baked at $230{ }^{\circ} \mathrm{C}$ for 30 min. It can be speculated that heating methods and temperatures make the differences in the chemical composition of bamboo culms caused by degrees of thermal degradation. Similar to other terpenes, both cyclosativene and $\alpha$-muurolene gave a terpene-like and woody olfactory impression in three Italian orchid species (Manzo et al. 2014) and Tarchonanthus camphoratus L. (Costa et al. 2008).

\section{Effects of Steaming Duration on Volatile Compounds of the Bamboo Culms}

Table 3 lists the volatile compounds released from the D. latiflorus, P. pubescens, and $P$. makinoi culms after steaming at $100{ }^{\circ} \mathrm{C}$ for different durations. As shown, no results for $D$. latiflorus steamed for $5 \mathrm{~min}$ were shown, indicating a low release of volatile constituents, insufficient for SPME analysis. In contrast, after 30-min and 60-min heating, benzenoids (67.87\% and $35.65 \%$, respectively) were observed as the major volatile compounds, followed by sesquiterpenes (10.10\% and $25.67 \%$, respectively). As shown in Fig. 2, phenylacetaldehyde was the dominant constituent in 30-min-steamed D. latiflorus, but its relative content decreased from $52.04 \%$ to $25.61 \%$ after steaming for another 30 min. In other words, a greater steaming duration led to more and different volatile compounds released, thus changing the major constituents and their relative contents. 
$P$. pubescens steamed for various durations showed different results and changes. As shown in Table 3, N compounds $(35.00 \%, 37.87 \%$, and $30.35 \%$, respectively) and sesquiterpenes $(11.28 \%, 24.11 \%$, and $36.12 \%$, respectively) were consistently the two main volatile compounds in $P$. pubescens steamed for $5 \mathrm{~min}, 30 \mathrm{~min}$, and $60 \mathrm{~min}$. In particular, the relative contents of the sesquiterpenes showed a positive correlation with steaming duration: increased steaming time led to increased sesquiterpene content. Among the $\mathrm{N}$ compounds in steamed $P$. pubescens, indole was the major constituent, whose relative contents remained between $30 \%$ and $40 \%$ at various steaming durations (Fig. 2 and Table 4). In contrast, $\alpha$-guaiene relative content increased with increasing steaming time. As shown in Table 4, the contents of $\alpha$-guaiene were $6.42 \%, 19.69 \%$, and $29.40 \%$ at $5 \mathrm{~min}, 30 \mathrm{~min}$, and $60 \mathrm{~min}$, respectively, again revealing a linear relationship between relative content and cooking time. These current findings echo previously reported results on increasing relative contents of volatile compounds in winter bamboo shoots with longer heating times (Chung et al. 2012).

Table 3. Volatile Compounds Released from D. latiflorus, P. pubescens, and P. makinoi Culms after Steaming at $100{ }^{\circ} \mathrm{C}$ for Different Durations

\begin{tabular}{|c|c|c|c|c|c|c|c|c|}
\hline \multirow{2}{*}{ Compounds } & \multicolumn{9}{|c|}{ Steaming Time (min) } \\
\cline { 2 - 9 } & \multicolumn{2}{|c|}{5} & \multicolumn{3}{c|}{30} & \multicolumn{3}{c|}{60} \\
\cline { 2 - 9 } & $\begin{array}{c}P . \\
\text { pubescens }\end{array}$ & $\begin{array}{c}P . \\
\text { makinoi }\end{array}$ & $\begin{array}{c}D . \\
\text { latiflorus }\end{array}$ & $\begin{array}{c}P . \\
\text { pubescens }\end{array}$ & $\begin{array}{c}P . \\
\text { makinoi }\end{array}$ & $\begin{array}{c}D . \\
\text { latiflorus }\end{array}$ & $\begin{array}{c}P . \\
\text { pubescens }\end{array}$ & $\begin{array}{c}P . \\
\text { makinoi }\end{array}$ \\
\hline Monoterpenes & & 0.28 & & & 0.75 & & & 0.69 \\
\hline Benzenoids & 10.49 & 0.19 & 67.87 & 14.56 & 0.31 & 35.65 & 9.76 & 0.23 \\
\hline Sesquiterpenes & 11.28 & 94.48 & 10.10 & 24.11 & 92.06 & 25.67 & 36.12 & 94.61 \\
\hline $\begin{array}{c}\text { Oxygenated } \\
\text { sesquiterpenes }\end{array}$ & 0.15 & & 7.24 & 0.56 & & 9.53 & 0.67 & \\
\hline N compounds & 35.00 & & 6.21 & 37.87 & & & 30.35 & \\
\hline Others & 10.59 & 1.06 & 2.39 & 6.27 & 1.13 & 4.26 & 4.83 & 0.95 \\
\hline Identified & 67.50 & 96.01 & 92.16 & 83.38 & 94.24 & 68.06 & 81.74 & 96.48 \\
\hline
\end{tabular}

In heated P. makinoi culms, sesquiterpenes (with relative contents of $94.48 \%$, $92.06 \%$, and $94.61 \%$ after 5-min, 30-min, and 60-min steaming, respectively) were consistently the dominant volatile compounds (Table 3). As mentioned above and shown in Table 2, P. makinoi steamed at $100{ }^{\circ} \mathrm{C}$ for 30 min comprised mainly cyclosativene (48.21\%), followed by $\alpha$-muurolene $(27.49 \%)$, and $\alpha$-copaene $(6.16 \%)$. Table 4 illustrates the trend of changes in these constituents at different steaming durations. As shown, the relative contents of $\alpha$-copaene remained rather constant, while those of cyclosativene and $\alpha$-muurolene showed opposite trends. With increases in steaming duration, the relative content of cyclosativene increased from $41.47 \%$ at $5 \mathrm{~min}$ to $48.21 \%$ at $30 \mathrm{~min}$, finally reaching $55.38 \%$ at $60 \mathrm{~min}$; meanwhile, those of $\alpha$-muurolene decreased from $35.16 \%$ to $27.49 \%$ and $26.51 \%$, respectively. Thus, cyclosativene relative content was positively related while $\alpha$-muurolene content was negatively related to heating time. 


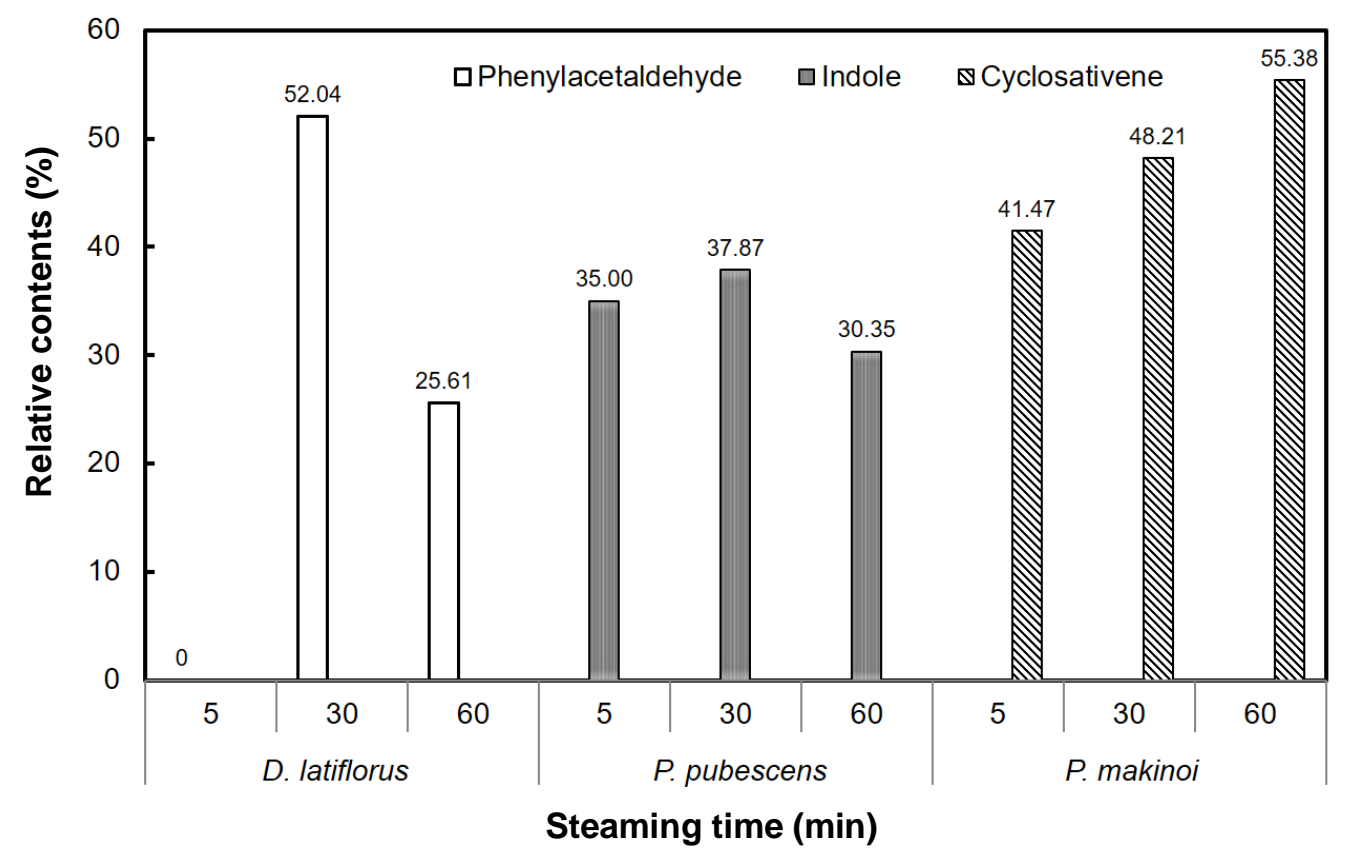

Fig. 2. Changes in major constituents and their relative contents (\%) of $D$. latiflorus, P. pubescens, and $P$. makinoi culms after steaming at $100{ }^{\circ} \mathrm{C}$ for different durations

\section{Effects of Baking Duration on Volatile Compounds of Three Bamboo Culms}

As shown in Fig. 3, there were 7, 8, and 18 volatile compounds released by the $D$. latiflorus culms after baking at $230{ }^{\circ} \mathrm{C}$ for $5 \mathrm{~min}, 30 \mathrm{~min}$, and $60 \mathrm{~min}$, respectively. Thus, there was a positive relationship between baking time and number of volatile compounds released. Increased baking time resulted in more volatile compounds released, along with a greater variety of aromas. Among the 7 volatile compounds released after the 5 -min baking at $230{ }^{\circ} \mathrm{C}, n$-nonanal $(22.70 \%)$ was the major constituent, followed by trans-2-hexen-1-al (18.83\%) and $n$-decanal (13.00\%). According to the study of Widjaja et al. (1996) on volatile components of non-fragrant and fragrant rices, $n$-nonanal has a floral, fruity odor. After the 30 -min baking at $230{ }^{\circ} \mathrm{C}$, phenylacetaldehyde, with a relative content of $48.42 \%$, became the main constituent. However, its relative content decreased to $32.22 \%$ with further baking, with other volatile compounds accounting for $41.43 \%$ of the compounds in D. latiflorus after the 60 -min baking at $230{ }^{\circ} \mathrm{C}$. This finding echoes the results for steamed culms, with more and different volatile compounds released when cooking time increased.

Changes in constituents and their relative contents of $P$. pubescens culms after baking at $230{ }^{\circ} \mathrm{C}$ for different durations are shown in Table 4 . As shown, both indole and $\alpha$-guaiene remained the two dominant constituents at various baking durations, but they showed opposite trends of changes in relative contents with cooking time. After 5-min, 30min, and 60-min baking, the relative contents of indole first increased from $50.69 \%$ to $52.41 \%$ and then decreased to $38.30 \%$, respectively; while those of $\alpha$-guaiene first decreased from $31.19 \%$ to $11.17 \%$ and then increased to $17.31 \%$, respectively. In addition to changes in relative contents, continuous baking also results in emergence and disappearance of volatile compounds. For instance, phenylacetaldehyde was not observed after the 5-min baking but was released upon 30-min baking (10.74\%) and thereafter $(10.95 \%)$. In contrast, $E$-nerolidol which was released after the 5-min baking $(8.51 \%)$ was no longer observed upon 30-min baking and thereafter (Table 4). 


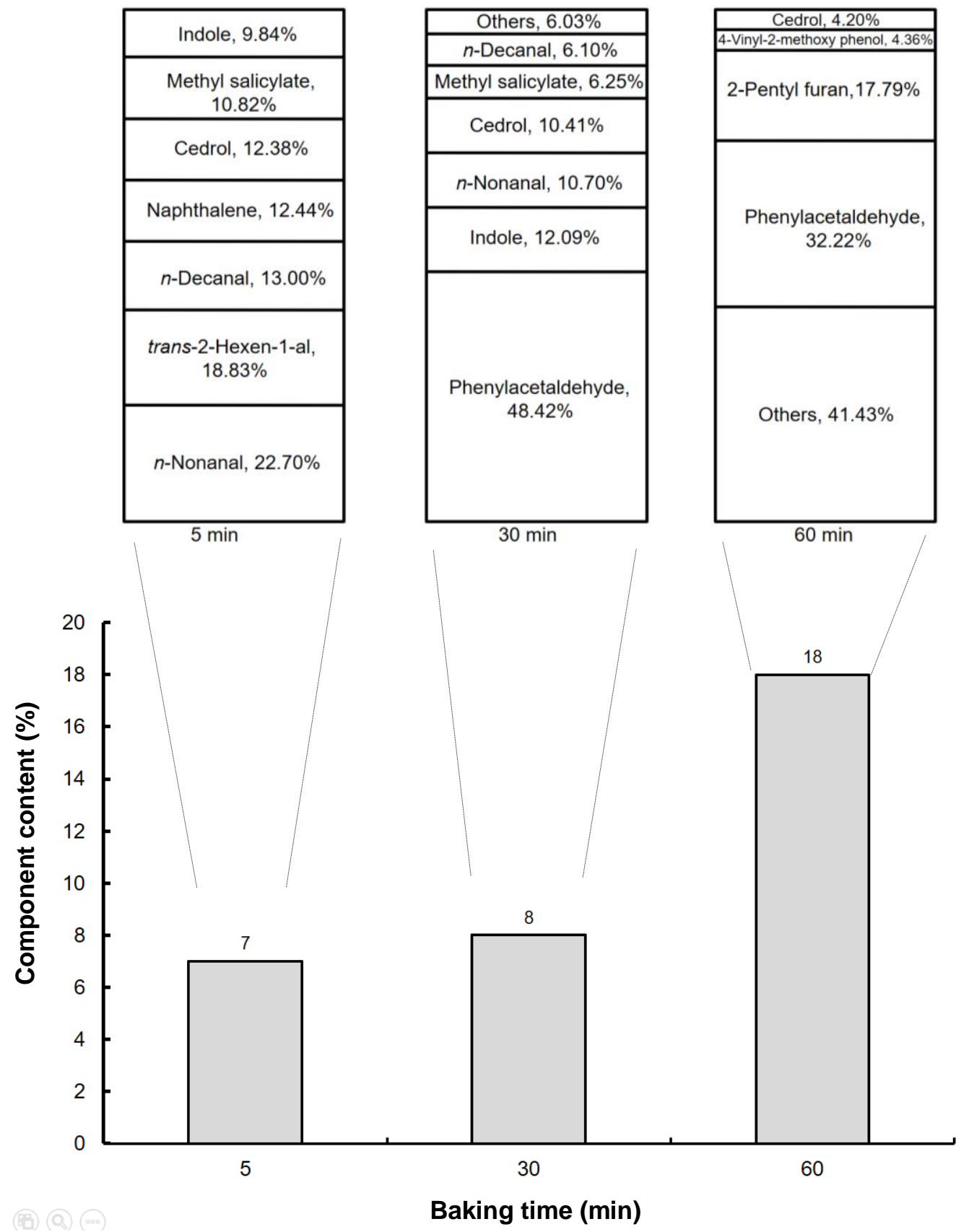

Fig. 3. Changes in constituents and their relative contents (\%) of $D$. latiflorus culms after baking at $230{ }^{\circ} \mathrm{C}$ for different durations 
Table 4. Changes in Constituents and Their Relative Contents (\%) of $P$. pubescens Culms after Heating for Different Durations

\begin{tabular}{|c|c|c|c|c|c|c|c|c|c|}
\hline \multirow{3}{*}{ Rt } & \multirow{3}{*}{$\mathrm{KI}^{\mathrm{a}}$} & \multirow{3}{*}{$\mathrm{rKI}^{\mathrm{b}}$} & \multirow{3}{*}{ Compounds } & \multicolumn{6}{|c|}{ Heating time (min) } \\
\hline & & & & \multicolumn{2}{|r|}{5} & \multicolumn{2}{|c|}{30} & \multicolumn{2}{|c|}{60} \\
\hline & & & & Steaming $^{c}$ & Baking $^{d}$ & Steaming $^{c}$ & Baking $^{d}$ & Steaming $^{c}$ & Baking $^{d}$ \\
\hline 12.22 & 963 & 960 & Benzaldehyde & & & & $0.23 \pm 0.09$ & & $2.27 \pm 2.03$ \\
\hline 15.57 & 1044 & 1042 & Phenylacetaldehyde & $7.18 \pm 2.91$ & & $12.77 \pm 4.70$ & $10.74 \pm 0.33$ & $7.89 \pm 1.80$ & $10.95 \pm 2.21$ \\
\hline 18.06 & 1104 & 1105 & $n$-Nonanal & $4.10 \pm 1.85$ & $0.77 \pm 0.39$ & $2.54 \pm 1.57$ & $0.80 \pm 0.14$ & $2.19 \pm 0.20$ & $1.50 \pm 0.65$ \\
\hline 20.12 & 1161 & 1161 & trans-2-Nonenal & $3.20 \pm 1.46$ & & $1.04 \pm 0.53$ & $0.52 \pm 0.17$ & & \\
\hline 21.27 & 1190 & 1192 & Methyl salicylate & $3.31 \pm 0.37$ & & $1.80 \pm 0.64$ & $1.79 \pm 0.34$ & $0.71 \pm 0.04$ & $1.19 \pm 0.42$ \\
\hline 21.87 & 1206 & 1201 & $n$-Decanal & $1.62 \pm 0.33$ & $0.16 \pm 0$ & $1.49 \pm 0.84$ & $0.26 \pm 0.07$ & $1.12 \pm 0.50$ & $0.50 \pm 0.08$ \\
\hline 24.81 & 1289 & 1290 & Indole & $35.00 \pm 6.77$ & $50.69 \pm 6.37$ & $37.87 \pm 2.93$ & $52.41 \pm 2.02$ & $30.35 \pm 10.45$ & $38.30 \pm 13.47$ \\
\hline 28.33 & 1392 & 1394 & Vanillin & & & & & $1.16 \pm 0.12$ & $0.72 \pm 0.47$ \\
\hline 29.16 & 1417 & 1419 & trans- $\beta$-Caryophyllene & $1.50 \pm 0.36$ & $3.53 \pm 0.21$ & $2.95 \pm 1.43$ & $1.37 \pm 0.32$ & $5.52 \pm 2.03$ & $2.22 \pm 0.69$ \\
\hline 29.68 & 1434 & 1439 & $\alpha$-Guaiene & $6.42 \pm 3.71$ & $31.19 \pm 6.82$ & $19.69 \pm 3.01$ & $11.17 \pm 2.87$ & $29.40 \pm 4.56$ & $17.31 \pm 5.39$ \\
\hline 30.33 & 1455 & 1454 & $\alpha$-Humulene & $1.58 \pm 0.46$ & & & & & \\
\hline 31.90 & 1503 & 1505 & $(E, E)$ - $\alpha$-Farnesene & & $0.61 \pm 0.33$ & & & & \\
\hline 32.13 & 1511 & 1513 & $\gamma$-Cadinene & $3.37 \pm 2.47$ & $0.63 \pm 0.16$ & $1.47 \pm 0.52$ & & $1.20 \pm 0.24$ & \\
\hline 33.60 & 1560 & 1563 & E-Nerolidol & & $8.51 \pm 2.96$ & & & $0.67 \pm 0.33$ & \\
\hline 34.81 & 1600 & 1600 & $n$-Hexadecane & $1.67 \pm 0.36$ & & $1.21 \pm 0.48$ & $1.03 \pm 0.21$ & $1.52 \pm 0.73$ & $0.68 \pm 0.06$ \\
\hline 41.83 & 1907 & & DT1 & & & & $0.27 \pm 0.06$ & & \\
\hline
\end{tabular}

${ }^{a}$ Kovats index relative to $\mathrm{C}_{9}-\mathrm{C}_{22} n$-alkanes on the DB-5ms column

bIdentification according to comparison of the mass spectrum, Kovats index on a DB-5ms column in Adams (2007), and co-injection with authentic compounds

'Steaming at $100^{\circ} \mathrm{C}$

dBaking at $230^{\circ} \mathrm{C}$

R.t.: Retention time ( $\mathrm{min}$ ) 


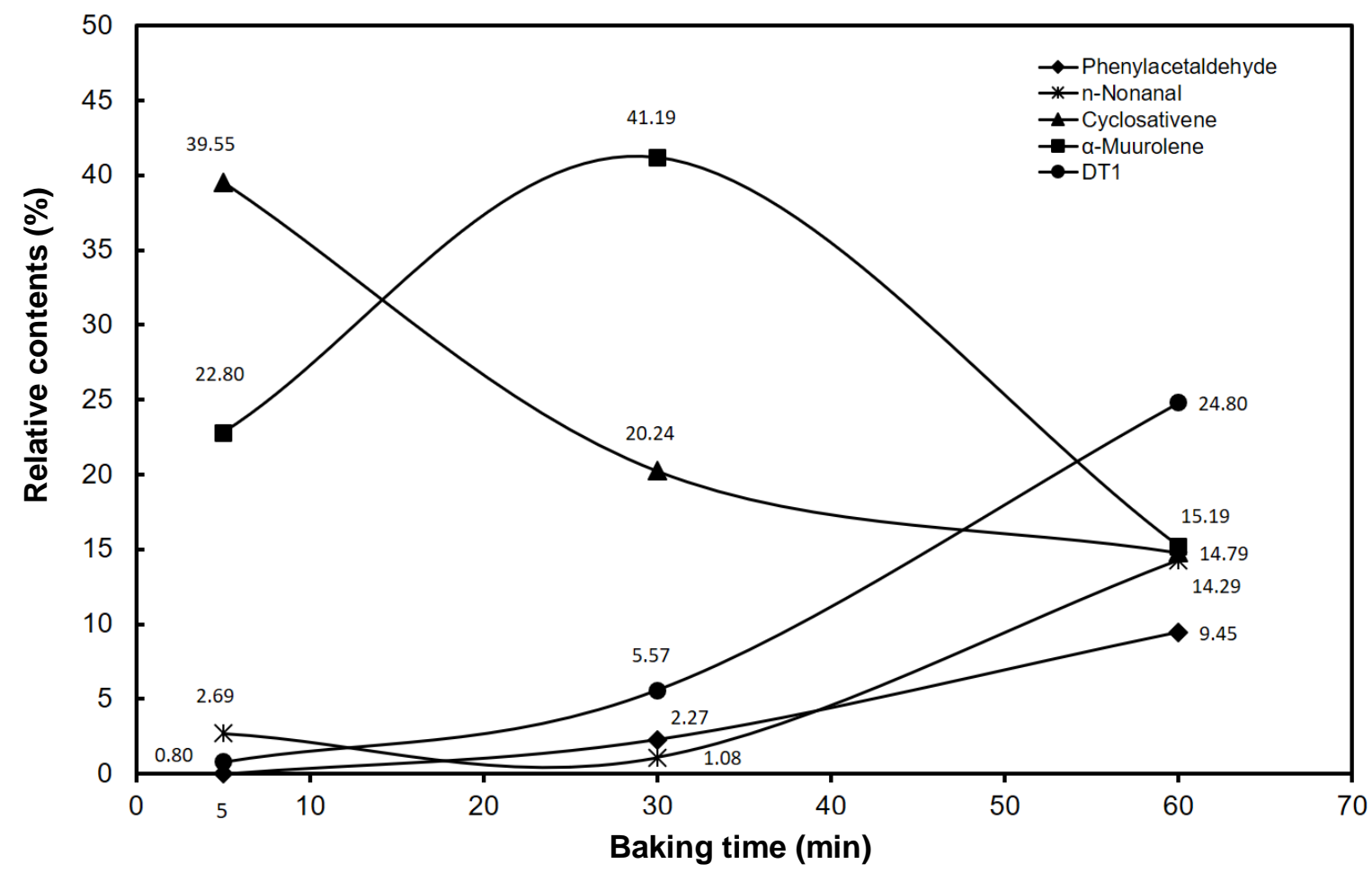

Fig. 4. Changes in major constituents and their relative contents (\%) of $P$. makinoi culms after baking at $230^{\circ} \mathrm{C}$ for different durations

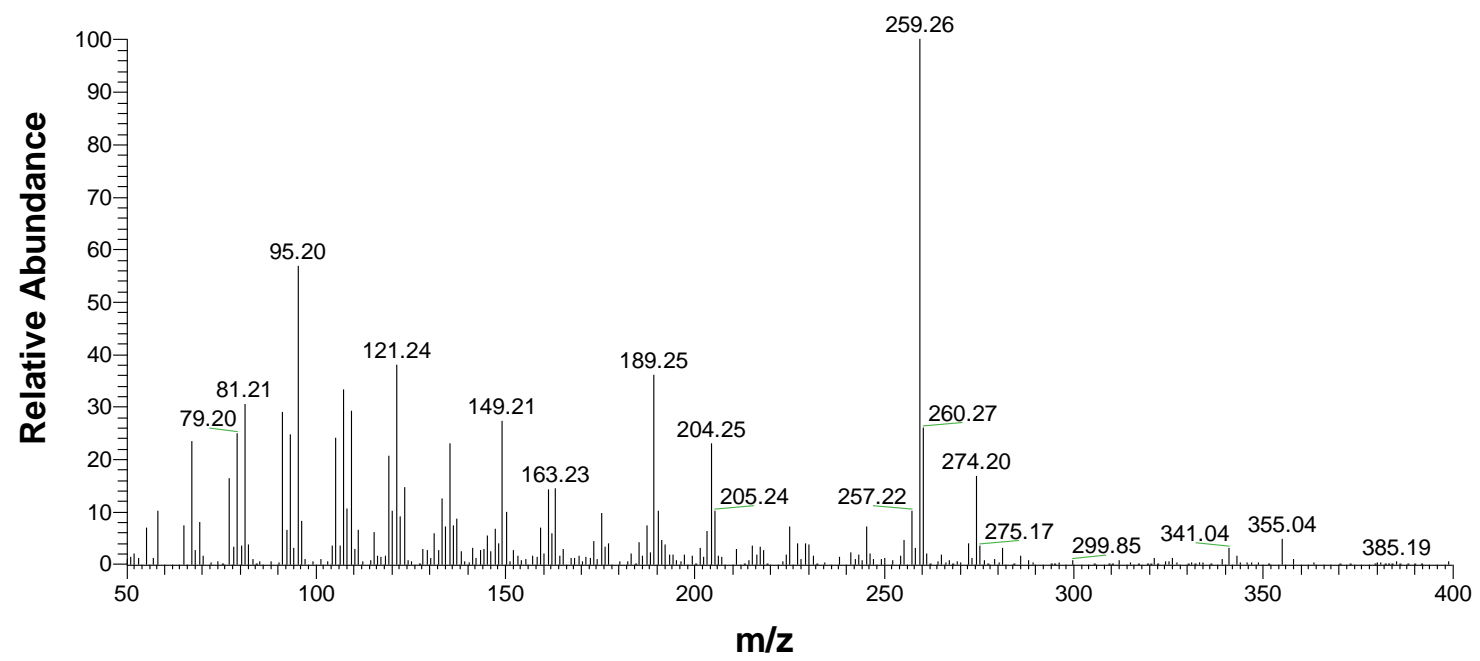

Fig. 5. MS spectrum of compound DT1

P. makinoi culms after baking at $230{ }^{\circ} \mathrm{C}$ for different durations also showed variations in constituents and their relative contents. As shown in Fig. 4, after 5-min baking, the culms comprised mainly cyclosativene $(39.55 \%)$, followed by $\alpha$-muurolene $(22.80 \%)$. However, further baking released more $\alpha$-muurolene $(41.19 \%)$ and less cyclosativene $(20.24 \%$ ), switching their predominance. Eventually, after the 60-min baking, DT 1 ranked highest in relative content, surpassing cyclosativene and $\alpha$ - 
muurolene. The release of DT 1 with the 5-min baking was only $0.80 \%$, but it increased steadily to $5.57 \%$ after $30 \mathrm{~min}$, reaching $24.80 \%$ at $60 \mathrm{~min}$. In summary, these three oncedominant constituents of baked $P$. makinoi culms all showed different trends of changes in relative content with baking duration. Relative content of cyclosativene was negatively related to baking time, while that of $\alpha$-muurolene first increased and then decreased. In other words, increased baking duration resulted in different fragrances being released. Little is known of DT 1 (Fig. 5), which merits further exploration on the type of compound to which it belongs and its characteristics.

\section{CONCLUSIONS}

1. GC-MS analyses show that all three bamboo culms released different aromas at ambient temperature depending on their respective dominant constituents. These volatile compounds also endow the bamboo culms with insect-repelling and antimicrobial properties, offering good protection and defense against hazards.

2. After 30-min steaming or baking at $100{ }^{\circ} \mathrm{C}$, P. makinoi culms comprised 22 and 24 volatile compounds, respectively, with $92.06 \%$ and $84.14 \%$ being sesquiterpenes. Cyclosativene $\left(48.21 \%\right.$ ) was the major constituent in $P$. makinoi steamed at $100{ }^{\circ} \mathrm{C}$ for $30 \mathrm{~min}$ but $\alpha$-muurolene $(41.19 \%)$ was the dominant one in $P$. makinoi baked at $230{ }^{\circ} \mathrm{C}$ for $30 \mathrm{~min}$. Both cyclosativene and $\alpha$-muurolene gave a terpene-like and woody odor.

3. The main volatile constituents in D. latiflorus and P. pubescens were benzenoids and N compounds, respectively. In $P$. pubescens whether steamed or baked, indole ranked highest in relative contents, it also had a characteristic mothball odor.

4. For steamed culms, it was clear that more and different volatile compounds were released when the cooking time increased. Taken together, the study results shed light on distinctive aroma released by $D$. latiflorus, P. pubescens, and P. makinoi culms when heated and provide useful references for promoting their use in cuisine preparation.

5. Different heating methods (steaming and baking) and heating times led to the variations in volatile components of the three bamboo culms. It is speculated that different volatile components produced from three bamboo culms may be due to the degrees of thermal degradation.

\section{ACKNOWLEDGEMENTS}

This study was supported by a Grant (109-C02) from the Experimental Forest, College of Bioresource and Agriculture, National Taiwan University, Taiwan, ROC. 


\section{REFERENCES CITED}

Abel, C., Clauss, M., Schaub, A., Gershenzon, J., and Tholl, D. (2009). "Floral and insectinduced volatile formation in Arabidopsis lyrata ssp. petraea, a perennial, outcrossing relative of A. thaliana," Planta 230(1), 1-11. DOI: 10.1007/s00425-009-0921-7

Adams, R. P. (2007). Identification of Essential Oil Components by Gas Chromatography and Mass Spectroscopy, Allured Publishing Corporation, Carol Stream, IL, USA.

Chen, Y.-J., Cheng, S.-S., and Chang, S.-T. (2010). "Monitoring the emission of volatile organic compounds from the leaves of Calocedrus macrolepis var. formosana using solid-phase micro-extraction," Journal of Wood Science 56(2), 140-147. DOI: 10.1007/s10086-009-1071-z

Choi, H.-S. (2006). "Lipolytic effects of citrus peel oils and their components," Journal of Agricultural and Food Chemistry 54(9), 3254-3258. DOI: 10.1021/jf052409j

Chung, M.-J., Cheng, S.-S., and Chang, S.-T. (2008). "Effects of four extraction methods on the constituents of essential oils from the leaves of Clausena excavate (in Chinese)," Forest Products Industries 27(4), 271-280.

Chung, M.-J., Cheng, S.-S., Lin, C.-Y., and Chang, S.-T. (2012). "Profiling of volatile compounds of Phyllostachys pubescens shoots in Taiwan," Food Chemistry 134(4), 1732-1737. DOI: 10.1016/j.foodchem.2012.03.120

Costa, R., Zellner, B. d., Crupi, M. L., De Fina, M. R., Valentino, M. R., Dugo, P., Dugo, G., and Mondello, L. (2008). "GC-MS, GC-O and enantio-GC investigation of the essential oil of Tarchonanthus camphoratus L," Flavour and Fragrance Journal 23(1), 40-48. DOI: 10.1002/ffj.1854

Crowell, P. L. (1999). "Prevention and therapy of cancer by dietary monoterpenes," The Journal of Nutrition 129(3), 775S-778S. DOI: 10.1093/jn/129.3.775S

do Vale, T. G., Furtado, E. C., Santos, Jr., J. G., and Viana, G. S. B. (2002). "Central effects of citral, myrcene and limonene, constituents of essential oil chemotypes from Lippia alba (Mill.) N.E. Brown," Phytomedicine 9(8), 709-714. DOI: 10.1078/094471102321621304

Elson, C. E., Maltzman, T. H., Boston, J. L., Tanner, M. A., and Gould, M. N. (1988). "Anti-carcinogenic activity of d-limonene during the initiation and promotion/progression stages of DMBA-induced rat mammary carcinogenesis," Carcinogenesis 9(2), 331-332. DOI: 10.1093/carcin/9.2.331

Hakkou, M., Pétrissans, M., Zoulalian, A., and Gérardin, P. (2005). "Investigation of wood wettability changes during heat treatment on the basis of chemical analysis," Polymer Degradation and Stability 89(1), 1-5. DOI: 10.1016/j.polymdegradstab.2004.10.017

Hsu, Y.-W., Chen, Y.-J., Wu, K.-T., and Chang, S.-T. (2006). "Application of solid phase microextraction technique to the analysis of biogenic volatile organic compounds (in Chinese)," Quarterly Journal of Chinese Forestry 39(2), 279-292. DOI: 10.30064/QJCF.200606.0010

Huang, W., Wu, Y, Zhao, Z., Yi, S., and He, Z. (2016). "Influence of thermal treatment conditions on the release of volatile organic compounds from bamboo," BioResources 11(3), 7296-7304. DOI: 10.15376/biores.11.3.7296-7304

Ibrahim, M. A., Kainulainen, P., and Aflatuni, A. (2001). "Insecticidal, repellent, antimicrobial activity and phytotoxicity of essential oils: With special reference to limonene and its suitability for control of insect pests," Agricultural and Food Science 10(3), 243-259. DOI: 10.23986/afsci.5697 
Manzo, A., Panseri, S., Vagge, I., and Giorgi, A. (2014). "Volatile fingerprint of Italian populations of orchids using solid phase microextraction and gas chromatography coupled with mass spectrometry," Molecules 19(6), 7913-7936. DOI: 10.3390/molecules19067913

Maraval, I., Mestres, C., Pernin, K., Ribeyre, F., Boulanger, R., Guichard, E., and Gunata, Z. (2008). "Odor-active compounds in cooked rice cultivars from Camargue (France) analyzed by GC-O and GC-MS," Journal of Agricultural and Food Chemistry 56(13), 5291-5298. DOI: 10.1021/jf7037373

Moon, S.-Y., Cliff, M. A., and Li-Chan, E. C. Y. (2006). "Odour-active components of simulated beef flavour analysed by solid phase microextraction and gas chromatography-mass spectrometry and -olfactometry," Food Research International 39(3), 294-308. DOI: 10.1016/j.foodres.2005.08.002

Rančić, A., Soković, M., Vukojević, J., Simić, A., Marin, P., Duletić-Laušević, S., and Djoković, D. (2005). "Chemical composition and antimicrobial activities of essential oils of Myrrhis odorata (L.) Scop, Hypericum perforatum L and Helichrysum arenarium (L.) Moench,” Journal of Essential Oil Research 17(3), 341-345. DOI: 10.1080/10412905.2005.9698925

Setzer, W. N., Schmidt, J. M., Noletto, J. A., and Vogler, B. (2006). "Leaf oil compositions and bioactivities of Abaco bush medicines," Pharmacologyonline 3, 794-802.

Steffen, A., and Pawliszyn, J. (1996). "Analysis of flavor volatiles using headspace solidphase microextraction," Journal of Agricultural and Food Chemistry 44(8), 2187-2193. DOI: $10.1021 /$ j9550727k

Takahashi, T., Mizui, K., and Miyazawa, M. (2010). "Volatile compounds with characteristic odour in moso-bamboo stems (Phyllostachys pubescens Mazel ex Houz. De ehaie)," Phytochemical Analysis 21(5), 489-495. DOI: 10.1002/pca.1224

Tu, N. T. M., Onishi, Y., Choi, H.-S., Kondo, Y., Bassore, S. M., Ukeda, H., and Sawamura, M. (2002). "Characteristic odor components of Citrus sphaerocarpa Tanaka (Kabosu) cold-pressed peel oil," Journal of Agricultural and Food Chemistry 50(10), 2908-2913. DOI: 10.1021/jf011578a

Wang, L.-F., Lee, J.-Y., Chung, J.-O., Baik, J.-H., So, S., and Park, S.-K. (2008). "Discrimination of teas with different degrees of fermentation by SPME-GC analysis of the characteristic volatile flavour compounds," Food Chemistry 109(1), 196-206. DOI: 10.1016/j.foodchem.2007.12.054

Widjaja, R., Craske, J. D., and Wootton, M. (1996). "Comparative studies on volatile components of non-fragrant and fragrant rices," Journal of the Science of Food and Agriculture 70(2), 151-161. DOI: 10.1002/(SICI)1097-0010(199602)70:2<151::AIDJSFA478>3.0.CO;2-U

Yang, D.-S., Lee, K.-S., Jeong, O.-Y., Kim, K.-J., and Kays, S.-J. (2008). "Characterization of volatile aroma compounds in cooked black rice," Journal of Agricultural and Food Chemistry 56(1), 235-240. DOI: 10.1021/jf072360c

Yang, X., and Peppard, T. (1994). "Solid-phase microextraction for flavor analysis," Journal of Agricultural and Food Chemistry 42(9), 1925-1930. DOI: 10.1021/jf00045a018

Article submitted: February 7, 2020; Peer review completed: April 3, 2020; Revised version received and accepted: April 17, 2020; Published: April 23, 2020.

DOI: $10.15376 /$ biores.15.2.4373-4387 